\title{
Thoughts toward a clinical database of architecture: evidence, complexity, and impact
}

\author{
Leonard R. Bachman
}

University of Houston, Houston, Texas

\begin{abstract}
This paper examines how architecture is building a clinical database similar to that of law and medicine and is developing this database for the purposes of acquiring complex design insight. This emerging clinical branch of architectural knowledge exceeds the scope of everyday experience of physical form and can thus be shown to enable a more satisfying scale of design thinking. It is argued that significant transformational kinds of professional transparency and accountability are thus intensifying. The tactics and methods of this paper are to connect previously disparate historical and contemporary events that mark the evolution of this database and then to fold those events into an explanatory narrative concerning clinical design practice. Beginning with architecture's use of precedent (Collins 1971), the formulation of design as complex problems (Rittel and Webber 1973), high performance buildings to meet the crisis of climate change, social mandates of postindustrial society (Bell 1973), and other roots of evidence, the paper then elaborates the themes in which this database is evolving. Such themes include post-occupancy evaluation (Bordass and Leaman 2005), continuous commissioning, performance simulation, digital instrumentation, automation, and other modes of data collection in buildings. Finally, the paper concludes with some anticipated impacts that such a clinical database might have on design practice and how their benefits can be achieved through new interdisciplinary relations between academia and practice.
\end{abstract}

Conference theme: Collaborative and Interdisciplinary Research

Keywords: evidence, complexity, accountability, non-local scale

\section{INTRODUCTION}

This paper examines the advent and evolution of architectural knowledge bases as they equate to the clinical databases found in professions such as law and medicine. The term clinical is initially defined here as the application of a body of knowledge to the diagnosis and therapeutic treatment of a specific problem case. A practitioner in this sense is a clinician.

Organizationally, the discussion first elaborates some evidence establishing how and why these sets of architectural knowledge are already accumulating. Second is an exploration of existing architectural databases and their clinical application in design. Next, discussion speculates on the impacts of clinical perspectives on architectural practice. Finally, a disciplinary model of architecture is offered to bridge between the profession and academia.

Law and Medicine are relevant examples of professions with essential clinical databases. Medicine has the most prolific set, with epidemiology, pharmacology, toxicology, and so forth; all of which refer back to the health treatment of individual cases through principles of anatomy, biology, and chemistry; just as architecture refers back to the vitality of individual building cases through thermodynamics, statics, acoustics, and so forth. Each health case is as unique as each building case... and then again; both medicine and architecture operate on generalizable principles. In medicine this generalizing is termed casuistry, referring to matters based collectively on the study of actual cases or case histories. An emphasis on use of medical research in clinical practice has spawned the field of Evidence Based Medicine (EBM). A later section of this paper examines the opportunities and dilemmas of EBM as perceived in the medical field and as applicable to architecture.

The clinical database of law is nicely translated into architecture through Peter Collins book, Architectural Judgement (1971). Collins compares the use of precedent in law to that of precedent buildings in architecture. William Hubbard endorses Collins' take on the model of law as analogous to that of architecture: "what we want in both fields... is work that reflects and responds to change yet gives the impression of continuity" (Hubbard 1981:91). As in medicine, each application of the law to a particular situation is simultaneously unique and generalizable... again, just as in architecture. So where medicine has its various specialized databases, law will have similar divisions of case precedents such as civil, criminal, tax, and so forth. Both legal and medical data sets provide a 
compendium of wisdom and history upon which new decisions can be intelligently based and without which judgement is only negligently decided.

To begin tracing the emergence of this clinical perspective in architecture, consider the words of Charles Garnier, speaking on the acoustics of his design for the 1889 Paris Opera. In the full spirit of trial and error, Garnier proclaimed a separation between the formal and performal tenets of architecture (Athanasopulos 1983: 26):

I must explain that I have adopted no principle, that my plan has been based on no theory, and that I leave success or failure to chance alone.

Today, some 120 years later, architects are gradually but decisively reversing this separation of the visibly tangible forms of their works from the invisible dynamics that buildings always manifest. There is a connecting of formal and performal thinking underway and a developing reliance on new kinds of unified insight that can inform and inspire design.

What is being connected? On one hand is the immediate and tactile experience of architecture as material, form, and space; that which is normally thought of as the perceptible and sensual aspects of architecture and which forms the conventional ambition of designers. On the other hand is the equally real but far less visual dimension of dynamic relations that a building embodies and then sets in play, such as the interrelated flows of energy, heat, light, air, sound, people, information, etc. In architecture this second invisible realm is usually linked to aspects of phenomenology as advocated by Christian NorbergSchultz's Genius Loci (1980) along with the writings of Zumthor, Holl, Leatherbarrow, Harries, Perez-Gomez and others.

Early evidence of this invisible and ephemeral second dimension was discussed in Norberg-Schulz's, Intentions in Architecture (1966) as the "filters, barriers, and switches" that make up building envelopes. Stephen Groák then invoked a complex systems view of these dynamics as "flow" in The Idea of Building (1992) as a formless and immaterial system of conduits, reservoirs, capacitors, and barriers. Still later, John Tillman Lyle asserted the Regenerative Design (1994) mandate of designing form to manifest process and flow. Most recently, Ralph Knowles furthers the discussion by describing the interplay of seasonal variation and human habitation in Ritual House (2006).

An more metaphysical context for these reconnected formal and performal dimensions of design can be interpreted from David Bohm's Wholeness and the Implicate Order (1980) wherein physical form is an "explicate order" that has been unfolded into the world of direct perception, versus dynamic or "implicate order" consisting of immaterial dynamic relations. For ease of discussion, Bohm's implicate order can be thought of as parallel to the probabilistic cosmology arising from the study of particle physics and quantum theory (e.g. Heisenberg's uncertainty principle of 1926). In this perspective, physical form is a lower "explicate" order experienced at the local scale of immediate perception. The dynamic and performal, or "implicate" order of systemic flows then is evidenced at a higher macro scale of reality in terms of flow and relation. In plain architectural lingo, this macro scale is a "non-local" perspective of change, relation, interaction, and adaptation... all beyond the ordinary direct sensual perception.

Returning to the reconnection of these two dimensions and to the emerging clinical database in architecture, note that it is only in their complementary wholeness that the full reality of architecture is confronted. Limiting design to one or the other as a single focus is reductive and mechanistically simplistic. Garnier's technical and scientific innocence of acoustics at the opera house can be easily excused; it would be another decade before Wallace Sabin would instigate the study of indoor acoustics. For the modern practitioner however, the paired mandates of formal and performal realities are here to stay. It only remains to accept them as complementary aspects of the same thing and to treat their duality as generative and synergistic.

\section{THE ROOTS OF EVIDENCE}

Clinical knowledge of architecture and the growth of a database to capture that knowledge are both rooted in progressive historical and evolutionary forces. This section briefly enumerates some fundamental influences of these trends.

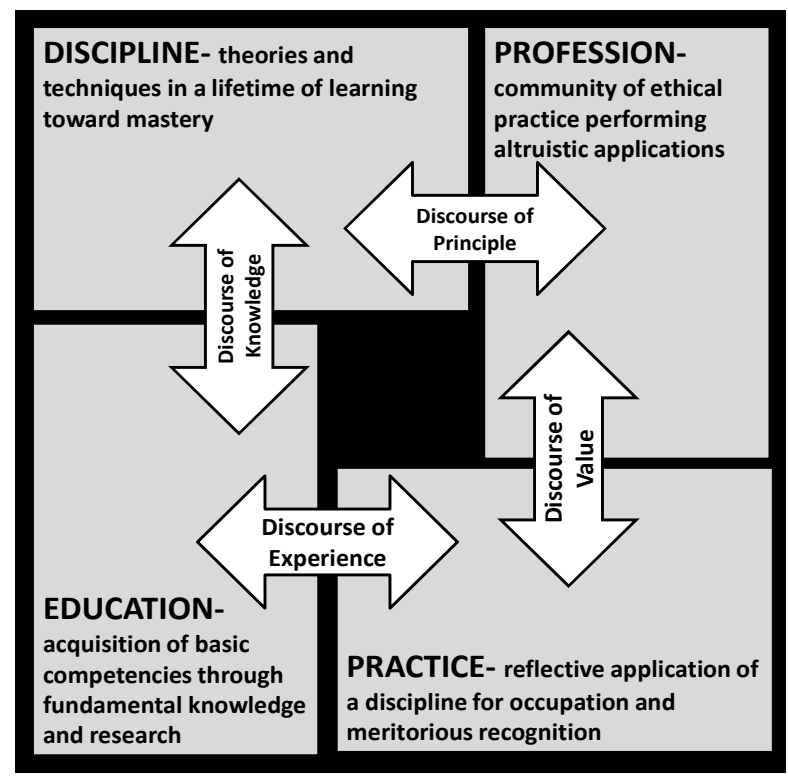

Figure 1: A framework for disciplinary knowledge.

\subsection{History}

In its roots, architecture as a profession is given society's license and monopoly in the design of the built environment (Fig. 1). Like any profession, this license is granted on the basis of its practitioners having acquired a large and difficult body of knowledge and committed 
to a lifetime of learning, refining, and growing this knowledge base. This contract is actualized in the architect's livelihood and occupation in service to society through application of that knowledge. This framework is familiar to readers of such works as Piotrowski and Robinson's edited volume, The Discipline of Architecture (2001) or Rapoport's essay on The Cultural Responsiveness of Architecture (1987). Objections as to the disciplinary nature of architecture have certainly been made on the grounds that architecture is dominated not so much by the lower two realms of knowledge, declarative or procedural, as by implicit understanding, sensitivity, and sensibility. But these objections simplistically overlook the fact that any profession is anchored in the third and higher realm of structural knowledge; knowing "what and how" are normative, but knowing "why" is critical. So in the end architecture is comprised of a body of built and unbuilt work upon which its contributions can be judged. That body of work and the critical assertions of its value are, therefore, the disciplinary root of the profession, just as the epistemological basis of any profession is so rooted in its progress, accomplishments, and seminal works. Obviously, architecture builds its body of knowledge, or what Walter Gropius called "the accumulated wisdom of architecture," by different methods than do law or medicine. Similar questions are asked concerning how architecture is like the model of art or the model of science. What matters in this discussion is only that such knowledge does exist and is identifiable.

Historically then, the knowledge base of architecture has accumulated with time and with lessons learned. Initially this knowledge was knit into a contract with the cultural elite rather than with society in general. That is to say, architects worked more toward the shared experiences and values of the privileged classes than toward the infrastructure and well being of society and for the built environment at large. Architectural service directly to the general population and to civic institutions is a more recent phenomenon.

As an accumulation of knowledge and wisdom, service to culture and privilege is rooted in the epicurean pleasure principle of celebration. In that context the essential value of knowledge, function, economy, and suitability is subsumed by desire for status, glory, and monumentality, all at any cost. In these modern and more democratic times however architects are engaged increasingly more by the transformation of essential requirements into built forms that are meaningful, serviceable, and yet still as masterful as the monumental works dedicated to culture. It is these later works that have instigated and formalized the clinical knowledge of architecture. Along the way, several new and important societal forces also asserted themselves, such as building codes, legal liability, technical society, and licensure. Most historically important perhaps was the eventual promotion of architecture to full ranking as a profession by its taking membership in the academy (Fisher 2008).

\subsection{Performance}

A second root of evidence for the emergence of architecture's clinical database is found in the measured performance of buildings. It is a relatively easy point: architects design buildings to work, to do something instrumental.

So long as the historical role of architecture was one of service to cultural appetites and privileged resources, the mandate of functional performance was an assumed fait-accompli and weak force. With the ascent of social and civic service however, the practical operation and performance of a building becomes increasingly important. With the simultaneous advent of technology and the means of measuring performance, it becomes easier to ask questions about performance, measure results, and to track performance over time. Finally, with the development of qualitative research methods and statistical tools, architects can empirically inquire and critique the value of more than just quantitative factors such as energy use. Qualitative issues such as human perception and environmental behaviour are now also on the table. And when the answers are easier to attain, the questions become much more compelling.

\subsection{Society}

Having invoked social transformation as a shift toward data driven design in a both an historic and a performative context, some specific influences in current events should be referenced. The characteristics of our emerging postindustrial society fulfil this need quite nicely (Bell 1973).

Table 1: The overlay of industrial and post-industrial society in the context of architecture. Source:

(Bachman 2006)

\begin{tabular}{|c|c|}
\hline $\begin{array}{l}\text { Industrial } \\
\text { Establishment }\end{array}$ & $\begin{array}{l}\text { Post-Industrial } \\
\text { Emergence }\end{array}$ \\
\hline \multicolumn{2}{|l|}{ Planning } \\
\hline Sustenance from nature & Sustainability with nature \\
\hline Anthropocentric & Biocentric \\
\hline Linear production & Cyclical flows \\
\hline Tactical objectives & Strategic goals \\
\hline Short-term plan & Long-term plan \\
\hline Incremental shifts & Continuous change \\
\hline \multicolumn{2}{|l|}{ Practice } \\
\hline Product and tradition & Process and discipline \\
\hline Local effects of action & Global interaction \\
\hline Mechanistic relationships & Systemic relationships \\
\hline Machine as the icon & Nature as the icon \\
\hline Heuristic procedures & Cybernetic integration \\
\hline Physical prototyping & Simulation modeling \\
\hline Mass standardization & Mass customization \\
\hline \multicolumn{2}{|l|}{ Design } \\
\hline Hierarchical and linear & Holistic and non-linear \\
\hline Deterministic simplicity & Teleologic complexity \\
\hline Intuitive heuristics of form & Self-emergent form \\
\hline Inevitable future & Future scenarios \\
\hline Innovative individuals & Transdisciplinary teams \\
\hline Pioneer-as-hero model & Designer-as-collaborator \\
\hline Design for elite status & Design for social justice \\
\hline Automatic control & Intelligent automation \\
\hline Transient static solutions & Robust dynamic solutions \\
\hline
\end{tabular}


Foremost among these characteristics is the transformation to a new system of value production, away from one primarily based on the value of industrial products and toward the value created by use of information. This refers not to the innate usefulness of information per se, but rather to what is attained in the intelligent collection, organization, and inference from data. This intelligence is what distinguishes mere data from useful information in the first place.

It is generally accepted that leading nations had already become pre-imminently information and service economies by the 1950's. More recent notions of knowledge professions, service workers, information technology, learning organizations, and globalization attest to further and deepening change. Architecture as a service profession is well aligned to capitalize on the now recognizable postindustrial notion of value creation (Table 1). The architect's actual ability do so however, may hinge on their willingness to point to a discreet body of captured and codified knowledge, ergo, a clinical database of architecture. Heretofore, the profession at large has been content, perhaps even secretly delighted, to maintain a kind of mystical, artistic, and cult driven air as to architectural knowledge. While the magic of making architecture will likely remain cloaked in professional acculturation, it is increasingly likely that the value of what architects produce and the knowledge base on which it is founded will have to become more explicit.

\subsection{Planning}

Another word for the operation of postindustrial intelligence is strategy, the plan of how knowledge will be collected, organized, and applied. Expectations of postindustrial society are that a strategic meta-plan for projects can be articulated at the proposal stage. This requires the architect to communicate in advance how delivery will occur, and by what processes and sequence. All of which presupposes the existence of a specialized knowledge base i.e., clinical database on which to operate.

At the level where this information targets the actual design, planning is increasingly expected to go beyond normative programming in the sense of creating an agenda for the client's wants and needs. The trend is for buildings to be more than static objects that house the user function. Rather, they are expected to facilitate the institution and operations of use in flexible ways, and respond to change and reorganization. Buildings will increasingly be seen less as status objects and more as integral parts of long range plans.

Consequently, there are new demands for information driven design. Design must facilitate long range scenario planning goals and objectives, what Buckminster Fuller called "inventing the future." Further, the information folded into such scenarios requires a participatory process involving not just the client owner's dictates, but rather a full spectrum of users, suppliers, consultants, and other related stakeholders. Themes elaborating how architects employ this planning based data are described in Section 2, below. The present point is that a foundational need for such data is driven first by a postindustrial notion of the value vested in pre-ordering such data, and secondly in the inclusive scope of sources from which that data is collected.

\subsection{Nature}

As Lyle (1994) recounted, architectural response to the knowledge structure of ecological fit traces to the work of biologist turned urban ecologist, Patrick Geddes. With Frederick Law Olmstead, Geddes presaged the advent of postindustrial times in the construct of history across "paleotechnic, technic, and neotechnic" epochs (Geddes 1915). Their description of linear industrial throughput in the technic era and cyclical looping of systems in the neotechnic are accurate mappings of what Bell later distinguished as industrial and postindustrial society.

To support the emergence of a clinical database in architecture, consider the stages of ecologically based design which architects have developed since Geddes: solar, passive, green, sustainable, and regenerative to name a broad but probably not complete list. While all of these relate in some way to the evidence of performance as discussed above, they also involve the knowledge base of an entire ethic. More than just energy efficiency, the broader scope of Design with Nature (McHarg 1969) has grown to include project specific data on indoor air quality, chemical sensitivity, eco-aesthetics, and so forth. It also involves measures at the global scale, such as carbon neutral, ecological footprint, and global warming.

Keeping abreast of this rapidly escalating issue and the continuously evolving information needed for appropriate design is not possible through traditional design thinking. It requires access to a database of vetted knowledge that allows for clinical application to specific cases, again, just as in medicine and in law.

\section{THEMES OF COMPLEXITY}

Tuning now to the sources of clinical knowledge in architecture, the four roots of evidence from the previous section can be illustrated in practice. While some of these current practices are not yet recognized as clinical databases, it is increasingly clear that they will eventually be thought of in that way.

The characteristics of clinical practice are adapted here from a description of how the clinical model is relevant in educational research (Elstein 1977). These traits will be useful in linking architectural design to clinical knowledge. To wit, a clinical practice is:

1. Problem initiated and problem directed

2. Concerned with action directed toward a particular problem and specific case

3. Performed collaboratively

4. Involved with collecting information and drawing conclusions

5. Performed diagnostically and therapeutically to identify and resolve disorders or discordance

6. Dependent on the clinician's interpretive reading of the problem and selection of an appropriate 
remedy

7. Based on a comprehensive body of collected cases that comprise a clinical database for practitioners

A medical description of clinical practice helps to summarize: "systematic and critical assessment, continuous experimentation, and subsequent revision of knowledge" (Maletrud 2001). Bearing these definitional characteristics in mind, the following paragraphs of this section detail how clinical databases are realized in architecture.

\subsection{Precedent}

Case method has long been a recognized clinical tool of medicine and law, and although the word "case" is seldom used in architecture in the same clinical way, the use of precursor design examples is well ennobled as "precedent." The difference in architectural case work with law and medicine is mostly semantic. Precedent in architecture allows access to theories about what is good design. Moreover, as Collins (1971) and Howard (1980) both show, precedent cases allow designers the opportunity to re-read and re-interpret previous works in innovative ways that lead to authentically new designs and new design thinking.

It happens then that history is, to a limited extent, a ready-made and naturally evolving clinical database of architecture. The caveat is that each precursor building case is not automatically recorded and written down in a clinical way. The designer's intention, the client's brief, the development plan, and even the success-inuse are often not made public. Frequently we are left with little more than post-hoc statements and knowledgeable but externally authored critique.

Several works of architectural literature do, nonetheless, focus on the development of particular typologies or particular architectural approaches, even sometimes on particular buildings. Each of these works uses some form of case study methodology to derive generalizable knowledge, and each case thus becomes a catalogued item in a clinical database, from where present and future architects can apply the codified knowledge to appropriate new cases.

\subsection{Postoccupancy evaluation}

Post-Occupancy Evaluation (POE) is defined as the assessment of a building directly through the perceptions of the actual user-occupants. POE is a detailed and systematic measurement performed after the occupants have had sufficient time to accommodate their activities to their new environment. POE provides an opportunity to identify lessons learned in the project outcomes as compared to the intended results. As such, POE is also a means of both verifying that the design intent was achieved and validating that the intent was appropriate in the first place. Studies of this sort have been undertaken since the late 1960s (Preiser 1999) and are increasingly seen as an integral part of the project process.

POE data is often proprietary in nature and such studies may contain confidential information as well as potentially litigious records of warranty concerning the outcomes. Nonetheless, many POE reports are made public through professional and academic channels. Two models for such accessible POE data would be academic research investigations and publically driven institutional inquiry. For the first model refer to the work originating with the Vital Signs Project and the case study database created at schools across the U.S. (University of California, Berkeley 2008) or the Integrated Building Technology library in Hong Kong (University of Hong Kong 2008).

For the second model on publically generated institutional POE studies, refer to the example of UK Usable Building Trust publications (The Building Trust 2008). Most notable here are the Postoccupancy Review of Building Engineering (PROBE) Studies which tie back to the 1963 Royal Institute of British Architects (RIBA) document, Plan of Work for Design Team Operation, which included a section on collecting feedback from recently occupied building projects (Bordass and Leaman 2005). By 2002, some 500 cases later, more than twenty PROBE studies had been published in the Building Services Journal. Other publications from the PROBE team are now appearing in the journal Building Research and Information. These Useable Building Trust PROBE efforts (principally by Bill Bordass and Adrian Leaman) typically entail full disclosure releases from all parties of the building team and the opportunity for the designers to respond to the findings. As such, the collected PROBE studies form an objective and foundational literature for a clinical POE database.

Taken as a whole then, POE first establishes a reliable body of evidence from which the practitioner-designer can interpretively read new problems then perform diagnostic and therapeutic resolution. Second, POE methodology has created new meta-knowledge on how to conduct such design studies, how to parse relevant information, and how to use such information to refine design knowledge. In either the academic case of Vital Signs or the public institutional case of PROBE, both examples point to a growing and potentially ubiquitous means of clinical architectural knowledge that could arguably be seen as requisite to best practice qualification.

\subsection{Continuous commissioning}

Commissioning studies and continuous commissioning investigations $(\mathrm{Cx})$ are performed to confirm that the current operation and control of a building is aligned with the current uses of the building. These are usually engineering level studies as they involve detailed knowledge of building systems and building physics. It has been demonstrated that commissioning is cost effective, particularly where there is continual change in how a building is used due to churn, operational changes, alterations in the institutional model, or technical modifications (Portland Energy Conservation 2002). It is not unusual for $C x$ to be considered essential to the delivery of an optimal building or to be incorporated into Total Quality Management practices.

Aside from the usual move-in adjustments and verification of building systems operation such as air 
balancing and light fixture aiming; commissioning is now practiced to insure whole building alignment. In this broader sense, commissioning work begins in the first conceptual design phase and runs through all phases of design, construction, move in, early operation, and is potentially repeated periodically throughout the life of the building. As a required and optionally advanced component of Leadership in Energy Efficient Design, (LEED) certification, a commissioning authority is appointed early on as an agent of the owner to anticipate, identify, and collaborate in the resolution of operational problems.

In the continuous commissioning mode, the host building and the occupant cohort are treated as two living entities. Each of the two involves complex and interactive dynamics, and they both play off one another in sometimes direct and sometimes subtle ways. Moreover, both the host and the occupant change with age, use, and modification. Optimizing the host-occupant relationship then requires annual or other periodic revisits.

The diagnostic and therapeutic role of commissioning is thus a clinical practice. As the leader of the design team then, the architect must be expected to incorporate the protocols and lessons-learned knowledge issuing from commissioning practices. With time, a database inevitably evolves case-by-case. Commissioning and the meta-knowledge attained concerning how to align host building with occupant cohort form an evidentiary and therefore clinical database.

\subsection{Instrumentation and automation}

Precedent, POE, and CX demonstrate separate and distinct examples of clinical databases in architecture. Each has an underlying dimension of data acquisition, organization, and interpretation in design practice. To show how such databases evolve though, it is necessary to examine methods by which such data are acquired in the first place. This process begins with the advent of accurate and inexpensive digital instrumentation.

Digital instrumentation facilitates cybernetic feedback by enabling continual measurement and verification of how a building is being used, how controls are sensing conditions, and what the operation of the building does in response. Instrumentation furthers the feedback loop by storing these measurements digitally and making them readily available for analysis in formats as simple as a spreadsheet.

At the smallest level of instrumentation are devices that collect and log readings, and the related software that allows us to convert the raw collected data into visualizations, patterns, and statistical inferences. Miniature devices capable of collecting thousands of readings across months of time divided into designated intervals between measurements are now readily available, reliable, and affordable. They are also easy to use with interface software and USB connection to a computer. With a few such devices and a good plan for how to interpret the data, it is now easy to take temperature, light level, humidity, sound and other quantitative measurements and convert them into an accurate picture of building and occupant behaviour. At a second level of instrumentation, the everyday digital control and operation of buildings is itself a growing source of diagnostic feedback. Direct Digital Control (DDC) for example has been in use for more than twenty years. Systems such as these are used to automate the control logic of buildings, signal failure alarms, and to integrate the operation of several building systems such as lighting and security or energy use. Since these systems both sense building conditions and control equipment in response, they provide two way communications between the building and the building operators. And since DDC is recordable, it creates a continuous record of interactions.

The third level of instrumentation takes the building to the level of artificially intelligent robot. These systems can actually learn the building's use and response patterns and decide independently how to anticipate and optimize building operation. Where features of the building are dynamic, such as operable shading devices or dimmable glazing for example, the buildingas-robot can calculate the optimum balance of daylight versus solar heat gain and adjust the building components to suit.

Finally, it is increasingly likely and practical to allow for the building and the occupants to interact through a second generation of robotic interface. Feedback is provided at the Oberlin Center for Environmental Studies for example by a dashboard type monitoring system located near the entry. Here even passersby can observe real time data such as how much energy the building is producing with photovoltaics versus how much it is consuming.

Beyond this, the robot may soon become an animated genii-like avatar that appears on the building computer intranet. This building-to-occupant feedback and interaction could easily and beneficially be used to initiate occupant control of their own environment (Brager 2008). And of course the whole conversation would be a matter of record and potential diagnostics, a clinical database for better commissioning and for better design of the next building.

\section{IMPACT}

Having examined the root sources of clinical knowledge in architecture, compared design case knowledge with other disciplines, and then explored just a few examples of clinical design knowledge, this discussion now turns to a more speculative view on the impacts of clinical databases in architecture.

\subsection{Dilemmas}

In medicine, the term casuistry has been used to invoke a rich double meaning. The pejorative meaning is that of over-subtle, even dishonest or sophistic reasoning. This leads to a caveat on the proposition of clinical databases in any discipline. Medicine, for one, is having vigorous discourse on the difference between the rational scientific approach to clinical practice as 
contrasted to a more holistic and personalized approach (Malterud 2001). The question distinguishes expertise from wisdom very nicely.

In architecture as in law and medicine, the practitioner is engaged in a complex and indeterminate web of interrelated factors. These have been classified as wicked problems (Rittel and Webber 1973). In systems theory such indeterminate problems are seen as normal and accurate descriptions of the world. Our everyday mechanistic and simplistic view experienced as a heuristic experience of the world has been exposed as insufficient and shallow. The truth is better regarded as probabilistic, contingent, and situational. As discussed in the introduction of this paper, the complex world of interrelated networks is inherently more satisfying to the designer than the everyday one of first order perception; the implicate is valued over the explicate order; and critical insight is valued over normative rules.

Neither lawyers, doctors, architects, nor most other disciplines deal with simple mechanistic cause-andeffect, relationally organized challenges. Formulamatic or rule based procedures for delimiting the problemspace of complex problems, devising operations within that space, and even for defining a successful outcome are all to be denied. A contingent and flexible means of dealing with ambiguity is really what is needed. At the same time, the complex problem-space model also speaks strongly for the use of clinical evidence: Without case histories and clinical evidence it is after all, impossible to recognize the immutable determinates, from the irrelevant noise, from the fertile ambiguity.

\subsection{Accountability}

For some, the scary dark side of clinical evidence is the accountability it demands. When a bona fide database of such evidence is at hand, practitioners are professionally bound to it as the source of best practice. With such knowledge as currency, the designer can use the legal model of warrants to explain how they sanction or justify their design decisions. Without such knowledge, the designer is less accountable, but also more encumbered. That encumbrance results from being continually forced to construe warrants from the ground up.

As previously discussed, design warrants are now expected to be supported by evidence and best practice models. The mandates of precedent, POE, and $\mathrm{Cx}$, along with the availability of digital measuring tools, simulation modelling, survey methods, qualitative validity and so forth are looming close overhead. If tomorrow's designs do not embrace these clinical mandates then Postindustrial society will probably force them on architecture anyway.

\subsection{Collaborative opportunity}

Many other impacts of clinical knowledge could be discussed here: redistribution of services, collaborative design practices, specialization, and so on. In the limited scope of this paper however, only one will be offered. It is chosen in the spirit of the named conference theme: collaborative research between academia and the profession.

Figure 1 suggests that architecture, like any discipline, can be thought of as four domains connected by four first-order discourses. This model is derived primarily from the many seminal essays found in The Discipline of Architecture (Piotrowski and Robinson, ed. 2001). Applying this Figure 1 model to the current discussion illustrates how academia could be positioned as the cultivator and storehouse of disciplinary knowledge. In many ways this is already the case: schools generate most architectural literature, schools store that literature in libraries, schools provide a forum for fair critique. There is however far greater opportunity.

Continuing education can form a vital link between academia and practice, where occupational experience is traded for applied research, critical ideals, and updated knowledge. In the context of the profession, a new notion of internship has been proposed as a learning organization approach to a practice academy (Malecha 2005). This professional internship model would easily align with and complement the suggested continuing education link with practice.

Finally, as universities and schools of architecture continually reinvent themselves (Fisher 2008), colleges of architecture are investing in facilities such as laboratories and digital fabrication shops. It is unlikely in the near term that practice firms will own such facilities or would be willing to develop expertise and protocols for the use of such resources. Instead, these new academic laboratories and shops might well be the very meeting places where continuing education and internship program activities occur.

\section{CONCLUSION}

A disciplinary model of architecture implies a clinical database. This paper elaborates how forces have led to the evolution of such databases and the design practices that such evidence supports. Some large and growing components of such clinical knowledge have been illustrated by the examples of precedent building cases, POE, and Cx. Digital technology and qualitative assessment tools were discussed as the font of clinical data and best practice knowledge. Further speculation points to impacts including issues of accountability, complexity, and of expertise versus wisdom. Finally, a disciplinary model is offered for collaboration across the four domains of architecture, and it is suggested that this collaboration be hosted by specialized facilities in schools of architecture.

\section{ACKNOWLEDGMENT}

Professors Ralph Knowles, Marc Schiler, and Mark Childs stimulated and contributed many ideas that show up here. I take the blame where their thoughts are not well represented and am indebted for what does shine through. Special thanks to Mark for his recent insight on William Hubbard's work. Christine Bachman, my spouse and colleague, shared lots of critical conversation and many draft readings. I also 
wish to give a special thanks to the ARCC conference organizing committee at UTSA, namely Hazem Rashed-Ali and Shelley Roff.

\section{REFERENCES}

Athanasopulos, C. G. 1983. Contemporary Theater: Evolution and Design. Wiley: New York.

Bachman, L. 2006. Embracing Complexity: Strategic Design in Postindustrial Architecture. Proceedings of the ARCC/EAAE International Conference on Architectural Research. Philadelphia, PA.

Bell, D. 1973. The Coming of Post-industrial Society; a Venture in Social Forecasting. Basic Books: New York. Bohm, D. 1980. Wholeness and the Implicate Order. Routledge \& Kegan Paul: London ; Boston.

Bordass, B and Leaman, A. 2005. Making Feedback and Post-occupancy Evaluation Routine 1: A Portfolio of Feedback Techniques, Building Research \& Information,33:4,347-352.

Brager, G. 2008. Occupant Satisfaction and Control Strategies in Mixed-Mode Buildings, Proceedings of the 5th Windsor Conference: Airconditioning and the Low Carbon Cooling Challenge, Network for Comfort and Energy Use in Buildings, Windsor Great Park, UK

Collins, P. 1971. Architectural Judgement. University of Toronto Press: Toronto.

Elstein, A, et.al. 1977. Characteristics of the Clinical Problem Solving Model and its Relevance to Educational Research. Annual Meeting of the American Educational Research Association; New York.

Fisher, T. 2008. Design Thinking in the University. Talk given at the ACSA Administrators Conference, November 7: Savannah, GA.

Geddes, P. 1915 (1968). Cities in Evolution; an Introduction to the Town Planning Movement and to the Study of Civics. H. Fertig: New York.

Groák, S. 1992. The Idea of Building: Thought and Action in the Design and Production of Buildings. London ; E \& FN Spon: New York.

Hubbard, W. 1982. Complicity and Conviction: Steps Toward an Architecture of Convention. The MIT Press: Boston.

Knowles, R. 2006. Ritual House : Drawing on Nature's Rhythms for Architecture and Urban Design. Island Press: Washington, DC.

Lyle, J. T. 1994. Regenerative Design for Sustainable Development. John Wiley: New York.
Malecha, M. J. 2005. The Learning Organization and Evolution of Practice Academy Concepts. North Carolina State University College of Design: Raleigh, NC.

Malterud, K. 2001. The Art and Science of Clinical Knowledge: Evidence Beyond Measures and Numbers. Lancet 358, no. 9279: 397.

McHarg, I. L. 1969. Design with Nature. Natural History Press: Garden City, N.Y.

Norberg-Schulz, C. 1980. Genius Loci: Towards a Phenomenology of Architecture. Rizzoli: New York.

Piotrowski, A. and Robinson, J. W, ed. 2001. The Discipline of Architecture. University of Minnesota Press: Minneapolis, MN.

Portland Energy Conservation, Inc. 2002. Establishing Commissioning Costs. [cited 29 December 2008) Available

$<$ http://www.peci.org/Library/PECl NewConCx1 1002. $\underline{\mathrm{pdf}}>$

Preiser, W.F.E. (1999). Post-occupancy Evaluation: Conceptual Basis, Benefits and Uses. In: Stein, J.M., and Spreckelmeyer, K.F. (Eds.) Classical Readings in Architecture. New York: McGraw-Hill.

Rapoport, A. 1987. On the Cultural Responsiveness of Architecture. Journal of Architectural Education 41, no. 1 (Fall).

Rittel, H. W. J. and Webber, M. 1973. Dilemmas in a General Theory of Planning. 155-169, Policy Sciences, Vol. 4.

The Building Trust. Useable Buildings. [cited 28 December 2008]

Available <http://www.usablebuildings.co.uk/>

The University of California, Berkeley. Vital Signs Curriculum Materials Project. [cited 28 December 2008] Available < http://arch.ced.berkeley.edu/vitalsigns/>

The University of Hong Kong. Integrated Building Technology. [cited 28 December 2008]. Available <http: //www.arch.hku.hk/teaching/learn.htm 